\title{
Predictive Value of C-Reactive Protein-to-Albumin Ratio for Neonatal Sepsis
}

\author{
Tiewei Li ${ }^{1}, *$ \\ Xiaojuan $\mathrm{Li}^{1, *}$ \\ Yulei Wei' \\ Geng Dong' \\ Jianwei Yang' \\ Junmei Yang' \\ Panpan Fang' \\ Minglu $\mathrm{Qi}^{2}$ \\ 'Zhengzhou Key Laboratory of Children's \\ Infection and Immunity, Children's \\ Hospital Affiliated to Zhengzhou \\ University, Henan Children's Hospital, \\ Zhengzhou Children's Hospital, \\ Zhengzhou, People's Republic of China; \\ ${ }^{2}$ General Hospital of Taiyuan Steel \\ (Group) Co., Ltd., Taiyuan, 030000, \\ People's Republic of China \\ *These authors contributed equally to \\ this work
}

Correspondence: Panpan Fang Zhengzhou Key Laboratory of Children's Infection and Immunity, Children's Hospital Affiliated to Zhengzhou

University, Henan Children's Hospital,

Zhengzhou Children's Hospital, 33M

Waihuan East Road, Longhu, Zhengzhou, 4500 18, People's Republic of China

Tel +8637I855I5779

Email fang_panpan@।63.com

Minglu Qi

General Hospital of Taiyuan Steel (Group)

Co., Ltd., No. 7, South 2nd Lane, Yingxin

Street, Jiancaoping District, Taiyuan City,

030008, People's Republic of China

Tel +8635I2I39774

Email feiyuxiaotian109@163.com
Purpose: Previous studies have reported that C-reactive protein-to-albumin ratio (CAR) was a risk factor for sepsis in adults. However, little is known regarding the role of CAR in neonates with sepsis. The aim of this study was to explore the relationship between CAR and neonatal sepsis.

Patients and Methods: In this research, from January 2016 to February 2020, a total of 1076 neonates were enrolled at Henan Children's Hospital in China. Complete clinical and laboratory data were collected. To identify the potential independent risk factor for neonatal sepsis, multivariate logistic regression analysis was performed. Receiver operating characteristic (ROC) curve analysis was used to evaluate the prediction accuracy of CAR in identifying neonatal sepsis.

Results: CAR levels were higher in neonates with sepsis and showed a gradual increase among the control group, mild sepsis group and severe sepsis group. The prevalence of neonates with overall sepsis, mild sepsis and severe sepsis increased significantly from CAR tertile 1 to tertile 3. Multiple logistic regression analysis showed that CAR was an independent risk factor for the presence of sepsis $(\mathrm{OR}=10.144,95 \% \mathrm{CI} 4.151-24.790, \mathrm{P}<0.001)$ and severe sepsis $(\mathrm{OR}=1.876,95 \%$ CI 1.562-2.253, $\mathrm{P}<0.001)$. ROC curve analysis showed that $\mathrm{CAR}$ had a well discriminatory power in predicting sepsis (area under curve $(\mathrm{AUC})=0.74,95 \% \mathrm{CI}, 0.71-0.77, \mathrm{P}<0.001)$ and severe sepsis $(\mathrm{AUC}=0.70,95 \% \mathrm{CI}, 0.67-$ $0.74, \mathrm{P}<0.001)$.

Conclusion: CAR was an independent predictor for the presence and severity of neonatal sepsis.

Keywords: C-reactive protein-to-albumin ratio, neonatal sepsis, risk factor, severe sepsis

\section{Introduction}

Sepsis is a systemic inflammatory response syndrome caused by infection and accompanied by pathological inflammation and organ system dysfunction, which seriously threatens human health. ${ }^{1}$ Sepsis has become the primary cause of death in the non-cardiac intensive care unit, and its incidence rate of sepsis keeps increasing. ${ }^{2,3}$ Due to their immature immune system, neonates are more susceptible to infections. Therefore, a late diagnosis and treatment can further lead to neonatal sepsis. ${ }^{4}$ Neonatal sepsis is a serious and life-threatening disease, which accounts for $15.2 \%$ of all deaths in the neonatal period worldwide. ${ }^{5}$ An early diagnosis and treatment of neonatal sepsis can help prevent severe and lifethreatening complications, and subsequently, reduce mortality, which can also avert the need for unnecessary antibiotics. However, it is sometimes difficult to diagnose neonatal sepsis due to the unclear diagnostic criteria and un-specificity 
clinical signs. ${ }^{4}$ Blood culture remains the gold standard, although it requires a long waiting time and can be affected by multiple factors. ${ }^{6}$ Therefore, it is critical to identify rapid, sensitive, and specific new biomarkers.

C-reactive protein (CRP) is an acute-phase protein produced by the liver that increases in case of inflammation or infection in the body. Studies have demonstrated that CRP is a determining predictor and risk factor for sepsis in adults and newborns. ${ }^{7-9}$ Albumin (ALB) is another protein produced by the liver, which makes up $40 \%$ to $60 \%$ of the total proteins in the blood. ${ }^{10}$ Serum albumin concentration is frequently used as an indicator of malnutrition. ${ }^{11}$ Currently, many studies demonstrated that there also was a close correlation between ALB and inflammation. ${ }^{11-13}$ Fleck et al ${ }^{14}$ reported that adult patients with septic shock had a lower serum ALB level. The C-reactive protein-to-albumin ratio (CAR), as an emerging inflammation index, has attracted substantial attention. Yu et $\mathrm{al}^{15}$ reported that the CAR was an independent predictor for the presence of sepsis and postburn 30-day mortality in adult. However, there are few published data on the relationship between the CAR and neonatal sepsis. Thus, this study aims to investigate the role of the CAR in neonatal sepsis.

\section{Materials and Methods}

\section{Study Population}

This was a retrospective study conducted in Henan Children's Hospital (Zhengzhou, China). From January 2016 to February 2020, consecutive neonates suspected with sepsis were enrolled in this study. The inclusion criteria were described as follows: 1) neonates with suspected sepsis and 2) aged 1-28 days. Neonates with the following conditions were excluded from this study: (1) missing the clinical and laboratory data presented in this study and 2) subjects with other diseases, such as congenital heart disease, hematological system diseases, cancer and major congenital malformation. The study protocol complied with the Declaration of Helsinki and was approved by the hospital's ethics review board. All procedures included in this study were undertaken as part of routine clinical practice, and the data which could identify subjects were removed. We confirmed that all the data was anonymized and maintained with confidentiality; therefore, the requirement for informed consent has been waived because of the retrospective nature of the current study.

\section{Definition}

According to the published International Pediatric Sepsis Consensus, neonatal sepsis is defined as suspected or confirmed infection accompanied with $\geq 2$ systemic inflammatory response syndromes (SIRS). ${ }^{16}$ Severe sepsis was defined as sepsis plus one of the following: cardiovascular organ dysfunction, acute respiratory distress syndrome, two or more other organ dysfunctions. ${ }^{16}$ The rest of the population were served as the control group.

\section{Collection and Biochemical Analyses}

The following data were collected: 1) clinical information, including age, gender, weight, temperature, respiratory rate, heart rate, systolic blood pressure and diastolic blood pressure; 2) laboratory data at admission, including procalcitonin (PCT), CRP, aspartate aminotransferase (AST), alanine aminotransferase (ALT), total protein (TP), ALB, blood urea nitrogen (BUN), creatinine (CREA) and uric acid (UA). The methods for detecting those laboratory index have been described in our previous published study. ${ }^{17} \mathrm{CRP}$ values of $<0.8 \mathrm{mg} / \mathrm{L}$ (measurement limits) were considered as $0.7 \mathrm{mg} / \mathrm{L}$. PCT levels $>100 \mathrm{ng} /$ $\mathrm{mL}$ or $<0.02 \mathrm{ng} / \mathrm{mL}$ were considered as $101 \mathrm{ng} / \mathrm{mL}$ and $0.01 \mathrm{ng} / \mathrm{mL}$, respectively. CAR was calculated using the formula CRP/ALB.

\section{Statistical Analysis}

Quantitative variables were presented as the mean \pm standard deviation (SD) or medians (interquartile range) and analyzed using independent Student's $t$-tests, one-way ANOVA or Mann-Whitney $U$-test, depending on their distribution. Categorical variables were expressed as percentages $(n, \%)$ and were analyzed using Chi-square or Fisher's exact tests, as appropriate. The correlation between two continuous variables were examined using Pearson or Spearman correlation test. Multivariate logistic regression analysis using enter method was performed to evaluate if CAR was an independent risk factor for the presence and severity of neonatal sepsis. Variables with a $\mathrm{P}$ value $<0.05$ in the univariate logistic analysis were included in the multiple regression analysis. Prediction accuracy was evaluated using the area under the receiver operating characteristic (ROC) curves. The cut-off point showing the greatest accuracy was determined using Youden's index (sensitivity + specificity -1 ). The area under ROC curve (AUC) of the two variables were compared using Delong's test. All data analysis was performed 
using SPSS 22.0 software (SPSS Inc., Chicago, Illinois, USA). A two-sided $\mathrm{P}$ value of $<0.05$ was considered statistically significant.

\section{Results}

\section{Basic Characteristics of Study Subjects}

In this study, a total of 1076 neonates were enrolled. There are 652 males and 424 females, with a mean age of 9.0 (5.0, 16.0) days. According to whether they have been diagnosed with sepsis and the severity of sepsis, the subjects were divided into three groups: control group, mild sepsis group and severe sepsis group (Figure 1). The majority of them $(n=624,58.0 \%)$ were diagnosed with sepsis, of which 263 neonates were diagnosed with mild sepsis, and 361 neonates were diagnosed with severe sepsis. The remaining 452 neonates without sepsis were served as control. Basic clinical and laboratory data are presented in Table 1. Compared to control, neonates with sepsis were older and had a higher body temperature, respiratory rate, and heart rate $(\mathrm{P}<0.05)$. Biochemical analyses showed that the levels of PCT, CRP, BUN, UA, and CAR were significantly increased in neonates with sepsis $(\mathrm{P}<0.001)$. On the contrary, the concentration of TP, ALB, and CREA was decreased $(\mathrm{P}<0.05)$. Further analysis showed that neonates with severe sepsis exhibited significantly higher levels of PCT, CRP, BUN, CREA, $\mathrm{UA}$, and CAR $(\mathrm{P}<0.05)$, compared to neonates with mild sepsis. In those biochemical indicators, we found that only PCT, CRP, and CAR showed a significant progressive rise among the three groups $(\mathrm{P}<0.05)$.

\section{Association of CAR with Neonatal Sepsis}

To further investigate the relationship between the CAR and severity of neonatal sepsis, the subjects were classified into three groups, according to CAR tertiles. As shown in Table 2, neonates in tertile 3 had higher level of PCT $(\mathrm{P}<$ 0.001). Further analysis showed that the prevalence of overall sepsis increased significantly from $34.1 \%$ in tertile 1 to $80.2 \%$ in tertile 3 ( $\mathrm{P}<0.001)$. Moreover, the prevalence of mild sepsis and severe sepsis also showed a progressive increase from CAR tertile 1 to tertile 3, while the control group were more likely to be in tertile 1 and tertile $2(\mathrm{P}<0.001)$.

\section{Relationship Between CAR and Clinical Parameters}

In the general population, CAR was positively correlated with temperature $(r=0.117, \mathrm{P}<0.001)$, respiratory rate $(r=0.130, \mathrm{P}<0.001)$, heart rate $(r=0.127$, $\mathrm{P}<0.001), \operatorname{PCT}(r=0.473, \mathrm{P}<0.001)$, ALT $(r=0.067, \mathrm{P}=0.027)$ and BUN $(r=0.118$, $\mathrm{P}<0.001)$, and negatively correlated with DBP $(r=-0.077, \mathrm{P}=0.011)$ and $\mathrm{TP}(r=-0.553$, $\mathrm{P}<0.001)$ (Table 3 ). There was no significant correlations were identified between CAR and weight, SBP, DBP, and ALB. However, in the neonates with sepsis group, CAR was only positively correlated respiratory rate $(r=0.089, \mathrm{P}=0.026), \mathrm{PCT} \quad(r=0.448$, $\mathrm{P}<0.001)$ and BUN $(r=0.087, \mathrm{P}<0.001)$.

\section{Predictive Value of CAR for Neonatal Sepsis}

As shown in Table 4, univariate and multivariable binary logistic regression analysis was performed to evaluate the value of CAR in predicting the presence of neonatal sepsis. After adjusting age, temperature, heart rate, respiratory rate, weight, PCT, AST, ALT, TP, UREA and UA, CAR was proved to be an independent risk factor for the presence of

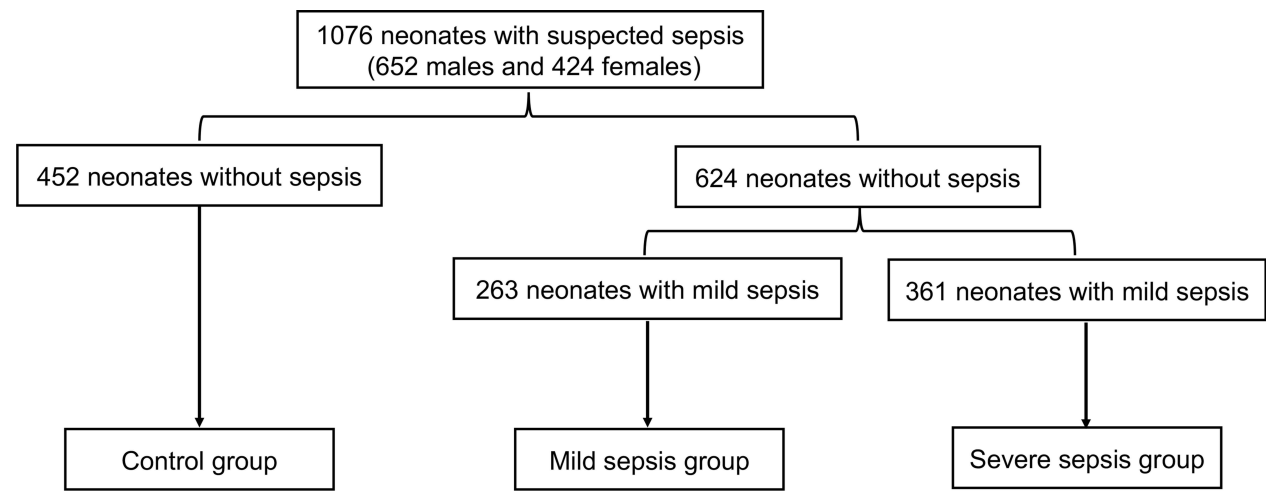

Figure I Study participant analysis of suspected sepsis neonates. 
Table I Basic Characteristics of Study Subjects

\begin{tabular}{|c|c|c|c|c|}
\hline \multirow[t]{2}{*}{ Variables } & \multirow[t]{2}{*}{ Control $(n=452)$} & \multirow[t]{2}{*}{ Sepsis $(n=624)$} & \multicolumn{2}{|c|}{ Sepsis } \\
\hline & & & Mild Sepsis $(n=263)$ & Severe Sepsis $(n=361)$ \\
\hline Age (days) & $7.0(4.0,12.0)$ & II.0 $(6.0, \mid 7.0)^{\mathrm{a}}$ & $11.0(6.0,19.0)^{c}$ & $11.0(6.0,16.0)^{d}$ \\
\hline Male, n (\%) & $264(58.4)$ & $388(62.2)$ & $170(64.6)$ & $218(60.4)$ \\
\hline Weight (kg) & $3.3 \pm 0.5$ & $3.2 \pm 0.6^{\mathrm{a}}$ & $3.3 \pm 0.6$ & $3.1 \pm 0.7^{\text {bd }}$ \\
\hline Temperature $\left({ }^{\circ} \mathrm{C}\right)$ & $37.0 \pm 0.5$ & $37.4 \pm 0.8^{\mathrm{a}}$ & $37.4 \pm 0.7^{c}$ & $37.3 \pm 0.8^{d}$ \\
\hline Respiratory (rate/minute) & $46.6 \pm 7.7$ & $49.8 \pm 10.1^{\mathrm{a}}$ & $49.4 \pm 9.6^{c}$ & $50.1 \pm 10.4^{d}$ \\
\hline Heart rate (bpm) & $142.8 \pm 16.1$ & $150.7 \pm|8 .|^{\mathrm{a}}$ & $149.7 \pm 17.6^{c}$ & $151.4 \pm 18.4^{d}$ \\
\hline $\mathrm{SBP}(\mathrm{mm} \mathrm{Hg})$ & $76.4 \pm 7.1$ & $76.3 \pm 8.1$ & $79.3 \pm 5.6^{c}$ & $74.1 \pm 9.0^{\mathrm{bd}}$ \\
\hline $\mathrm{DBP}(\mathrm{mm} \mathrm{Hg})$ & $46.7 \pm 7.4$ & $46.3 \pm 7.8$ & $47.8 \pm 7.5^{c}$ & $45.1 \pm 7.9^{\mathrm{bd}}$ \\
\hline PCT $(\mathrm{ng} / \mathrm{mL})$ & $0.14(0.09,0.23)$ & $0.30(0.14,1.52)^{\mathrm{a}}$ & $0.22(0.11,0.76)^{c}$ & $0.37(0.16,2.19)^{\mathrm{bd}}$ \\
\hline CRP (mg/L) & $0.7(0.7,0.7)$ & $0.7(0.7,14.1)^{\mathrm{a}}$ & $0.7(0.7,9.2)^{\mathrm{c}}$ & $0.7(0.7,17.3)^{\mathrm{bd}}$ \\
\hline Biochemical parameters & & & & \\
\hline AST (U/L) & $37.6(30.0,50.0)$ & $38.4(27.9,53.7)$ & $36.1(27.8,48.0)$ & $39.6(27.9,61.7)^{\mathrm{b}}$ \\
\hline ALT (U/L) & I5.I $(20.0,33.4)$ & $28.5(22.0,38.0)^{\mathrm{a}}$ & $28.6(22.3,36.2)^{c}$ & $28.5(21.9,39.6)^{d}$ \\
\hline $\mathrm{TP}(\mathrm{g} / \mathrm{L})$ & $57.1 \pm 6.1$ & $53.7 \pm 7.0^{\mathrm{a}}$ & $54.4 \pm 6.1^{c}$ & $53.3 \pm 7.6^{d}$ \\
\hline ALB $(g / L)$ & $33.7 \pm 4.0$ & $30.3 \pm 4.6^{\mathrm{a}}$ & $31.2 \pm 4.3^{c}$ & $29.7 \pm 4.7^{\mathrm{bd}}$ \\
\hline BUN (mM) & $2.2(1.4,3.3)$ & $3.1(1.9,4.3)^{\mathrm{a}}$ & $2.8(1.9,3.9)^{\mathrm{c}}$ & $3.2(1.9,4.8)^{\mathrm{bd}}$ \\
\hline CREA $(\mu \mathrm{M})$ & $50.1(41.3,57.6)$ & $45.5(36.0,60.3)^{\mathrm{a}}$ & $43.4(34.7,53.1)^{c}$ & $47.7(37.2,64.8)^{\mathrm{b}}$ \\
\hline UA $(\mu \mathrm{M})$ & 137.4 (103.0, 179.1) & $144.2(106.6,198.5)^{\mathrm{a}}$ & 143.5 (106.9, 185.4) & $145.5(106.5,208.4)^{d}$ \\
\hline $\operatorname{CAR}\left(10^{-3}\right)$ & $0.021(0.019,0.024)$ & $0.026(0.022,0.438)^{a}$ & $0.024(0.021,0.277)^{c}$ & $0.029(0.022,0.606)^{\mathrm{bd}}$ \\
\hline
\end{tabular}

Notes: All values are presented as the mean \pm SD or $\mathrm{n}(\%)$ or as the median (interquartile range). ${ }^{\mathrm{a}} \mathrm{P}<0.05$ for sepsis vs control. ${ }^{\mathrm{b}} \mathrm{P}<0.05$ for severe sepsis vs mild sepsis. ${ }^{c} \mathrm{P}<0.05$ for mild sepsis vs control. ${ }^{\mathrm{d}} \mathrm{P}<0.05$ for severe sepsis vs control.

Abbreviations: SBP, systolic blood pressure; DBP, diastolic blood pressure; PCT, procalcitonin; hsCRP, high sensitivity C-reactive protein; AST, aspartate aminotransferase; ALT, alanine aminotransferase; TP, total protein; ALB, albumin; BUN, blood urea nitrogen; CREA, creatinine; UA, uric acid; CAR, C-reactive protein-to-albumin ratio.

Table 2 The Presence and Severity of Neonatal Sepsis According to CAR Tertiles

\begin{tabular}{|c|c|c|c|c|}
\hline Variables & $\begin{array}{l}\text { Tertile I }\left(<0.021 * 10^{-3}\right) \\
\qquad(n=361)\end{array}$ & $\begin{array}{c}\text { Tertile } 2\left(0.021 * 10^{-3}-0.028 * 10^{-3}\right) \\
(n=356)\end{array}$ & $\begin{array}{c}\text { Tertile } 3\left(>0.028 * 10^{-3}\right) \\
\quad(n=359)\end{array}$ & $\boldsymbol{P}$ \\
\hline Age (days) & $9.0(6.0,14.0)$ & $8.0(5.0,15.0)$ & $10.0(5.0,16.0)$ & 0.524 \\
\hline Male, n (\%) & $204(56.5)$ & $213(59.8)$ & $235(65.5)$ & 0.046 \\
\hline PCT (ng/mL) & $0.13(0.09,0.21)$ & $0.17(0.11,0.35)$ & $0.52(0.19,3.15)$ & $<0.001$ \\
\hline \multicolumn{5}{|l|}{ Clinical data } \\
\hline Control, n (\%) & $238(65.9)$ & $143(40.2)$ & 71 (19.8) & $<0.001$ \\
\hline Overall sepsis & $123(34.1)$ & $213(59.8)$ & $288(80.2)$ & $<0.001$ \\
\hline Mild sepsis, n (\%) & $66(18.3)$ & $94(26.4)$ & $103(28.7)$ & $<0.001$ \\
\hline Severe sepsis, n (\%) & $57(15.8)$ & $119(33.4)$ & $185(5 \mid .5)$ & $<0.001$ \\
\hline
\end{tabular}

Abbreviations: SBP, systolic blood pressure; DBP, diastolic blood pressure; PCT, procalcitonin; hsCRP, high sensitivity C-reactive protein; AST, aspartate aminotransferase; ALT, alanine aminotransferase; TP, total protein; ALB, albumin; BUN, blood urea nitrogen; CREA, creatinine; UA, uric acid; CAR, C-reactive protein-to-albumin ratio.

sepsis $(\mathrm{OR}=10.144,95 \%$ CI 4.151-24.790, $\mathrm{P}<0.001)$. Meanwhile, CAR tertiles were also independently associated with an increased prevalence of neonatal sepsis.
Furthermore, our data also showed that CAR and CAR tertiles were independent risk factors for the presence of severe sepsis. 
Table 3 Correlations Between CAR and Clinical Parameters

\begin{tabular}{|c|c|c|c|c|}
\hline \multirow[t]{2}{*}{ Variables } & \multicolumn{2}{|c|}{$\begin{array}{c}\text { Overall } \\
\text { Population }\end{array}$} & \multicolumn{2}{|c|}{$\begin{array}{c}\text { Neonates with } \\
\text { Sepsis }\end{array}$} \\
\hline & $r$ & $\mathbf{P}$ & $r$ & $\mathbf{P}$ \\
\hline Age (day) & 0.011 & 0.717 & -0.038 & 0.343 \\
\hline Weight (kg) & -0.057 & 0.060 & -0.027 & 0.504 \\
\hline Temperature $\left({ }^{\circ} \mathrm{C}\right)$ & 0.117 & $<0.001$ & 0.015 & 0.717 \\
\hline Respiratory (rate/minute) & 0.130 & $<0.001$ & 0.089 & 0.026 \\
\hline Heart rate (bpm) & 0.127 & $<0.001$ & 0.076 & 0.061 \\
\hline $\mathrm{SBP}(\mathrm{mm} \mathrm{Hg})$ & -0.057 & 0.062 & -0.057 & 0.153 \\
\hline $\mathrm{DBP}(\mathrm{mm} \mathrm{Hg})$ & -0.077 & 0.011 & -0.033 & 0.416 \\
\hline РCT (ng/mL) & 0.473 & $<0.001$ & 0.448 & $<0.001$ \\
\hline AST (U/L) & -0.044 & 0.148 & -0.028 & 0.486 \\
\hline ALT (U/L) & 0.067 & 0.027 & 0.025 & 0.538 \\
\hline TP $(g / L)$ & -0.553 & $<0.001$ & -0.431 & $<0.001$ \\
\hline CREA $(\mu \mathrm{M})$ & -0.006 & 0.844 & 0.006 & 0.872 \\
\hline UA $(\mu \mathrm{M})$ & 0.038 & 0.208 & 0.014 & 0.727 \\
\hline BUN & 0.118 & $<0.001$ & 0.087 & 0.029 \\
\hline
\end{tabular}

Abbreviations: SBP, systolic blood pressure; DBP, diastolic blood pressure; PCT, procalcitonin; hsCRP, high sensitivity C-reactive protein; AST, aspartate aminotransferase; ALT, alanine aminotransferase; TP, total protein; ALB, albumin; BUN, blood urea nitrogen; CREA, creatinine; UA, uric acid; CAR, C-reactive protein-to-albumin ratio.

\section{Diagnostic Performance of the CAR for Neonatal Sepsis}

The prediction of neonatal sepsis was assessed using the AUC. As shown in Figure 2A, the AUC for the CAR was 0.74 (95\% CI, 0.71-0.77, P $<0.001)$, which was significantly higher than the AUC for CRP (AUC $=0.65,95 \%$ CI, $0.61-$
$0.68, \mathrm{P}<0.001)$ and ALB $(\mathrm{AUC}=0.71,95 \% \mathrm{CI}, 0.68-0.74$, $\mathrm{P}<0.001)(\mathrm{P}<0.05)$. The optimal cut-off value of $\mathrm{CAR}$ was 0.023 , with $69 \%$ sensitivity and $63 \%$ specificity. Additionally, the value of CAR in predicting severe sepsis was also evaluated. Compared to that for CRP and ALB, CAR showed good discriminatory power in predicting severe sepsis (AUC $=0.70,95 \% \mathrm{CI}, 0.67-0.74, \mathrm{P}<0.001$ ) (Figure $2 \mathrm{~B}$ ). The optimal cut-off value of CAR was 0.024 , with $69 \%$ sensitivity and $64 \%$ specificity. According to the cut-off value, subjects were divided into two groups: high CAR group and low CAR group. Further analysis showed that the prevalence of neonatal sepsis and severe sepsis was significantly higher in the high CAR group (Figure 3A and B).

\section{Discussion}

Sepsis still remains a serious and life-threatening disease, especially in newborns. Indeed, neonates are more prone to infections caused by both bacteria and viruses due to their immature immune systems, and are, therefore, more prone to develop neonatal sepsis. According to the report by Global Sepsis Alliance (GSA), infections leading to sepsis accounted for about one-fifth of the world's neonatal deaths, and raised up to $25 \%$ in South Asia and subSaharan Africa. ${ }^{18}$ However, the clinical signs of neonatal sepsis are multiple, nonspecific and include bradycardia, temperature instability, diminished spontaneous activity, less vigorous sucking, apnea, respiratory distress,

Table 4 Regression Analysis to Assess the Presence of Neonatal Sepsis and Severe Sepsis According to CAR Tertiles

\begin{tabular}{|c|c|c|c|c|}
\hline \multirow[t]{2}{*}{ Variables } & \multicolumn{2}{|c|}{ Univariate } & \multicolumn{2}{|c|}{ Multivariate* } \\
\hline & OR $(95 \% \mathrm{Cl})$ & $\mathbf{p}$ & OR (95\% Cl) & $\mathbf{p}$ \\
\hline \multicolumn{5}{|c|}{ Presence of sepsis } \\
\hline CAR & $20.596(8.304-51.085)$ & $<0.001$ & $10.144(4.15 \mathrm{I}-24.790)$ & $<0.001$ \\
\hline \multicolumn{5}{|c|}{ CAR tertiles } \\
\hline Tertile I & I & & I & \\
\hline Tertile 2 & $2.882(2.127-3.905)$ & $<0.001$ & $2.599(1.767-3.824)$ & $<0.001$ \\
\hline Tertile 3 & $7.849(5.593-11.014)$ & $<0.001$ & $5.166(3.406-7.837)$ & $<0.001$ \\
\hline \multicolumn{5}{|c|}{ Presence of severe sepsis } \\
\hline CAR & $1.876(1.562-2.253)$ & $<0.001$ & 1.391 (1.14I-1.696) & 0.001 \\
\hline \multicolumn{5}{|c|}{ CAR tertiles } \\
\hline Tertile I & I & & 1 & \\
\hline Tertile 2 & $2.678(I .87 I-3.833)$ & $<0.001$ & $2.416(1.587-3.677)$ & $<0.001$ \\
\hline Tertile 3 & $5.670(3.994-8.05 I)$ & $<0.001$ & $3.767(2.476-5.732)$ & $<0.001$ \\
\hline
\end{tabular}

Notes: *Adjusted for age, temperature, heart rate, respiratory rate, weight, PCT, AST, ALT, TP, UREA and UA.

Abbreviations: SBP, systolic blood pressure; DBP, diastolic blood pressure; PCT, procalcitonin; hsCRP, high sensitivity C-reactive protein; AST, aspartate aminotransferase; ALT, alanine aminotransferase; TP, total protein; ALB, albumin; BUN, blood urea nitrogen; CREA, creatinine; UA, uric acid; CAR, C-reactive protein-to-albumin ratio. 

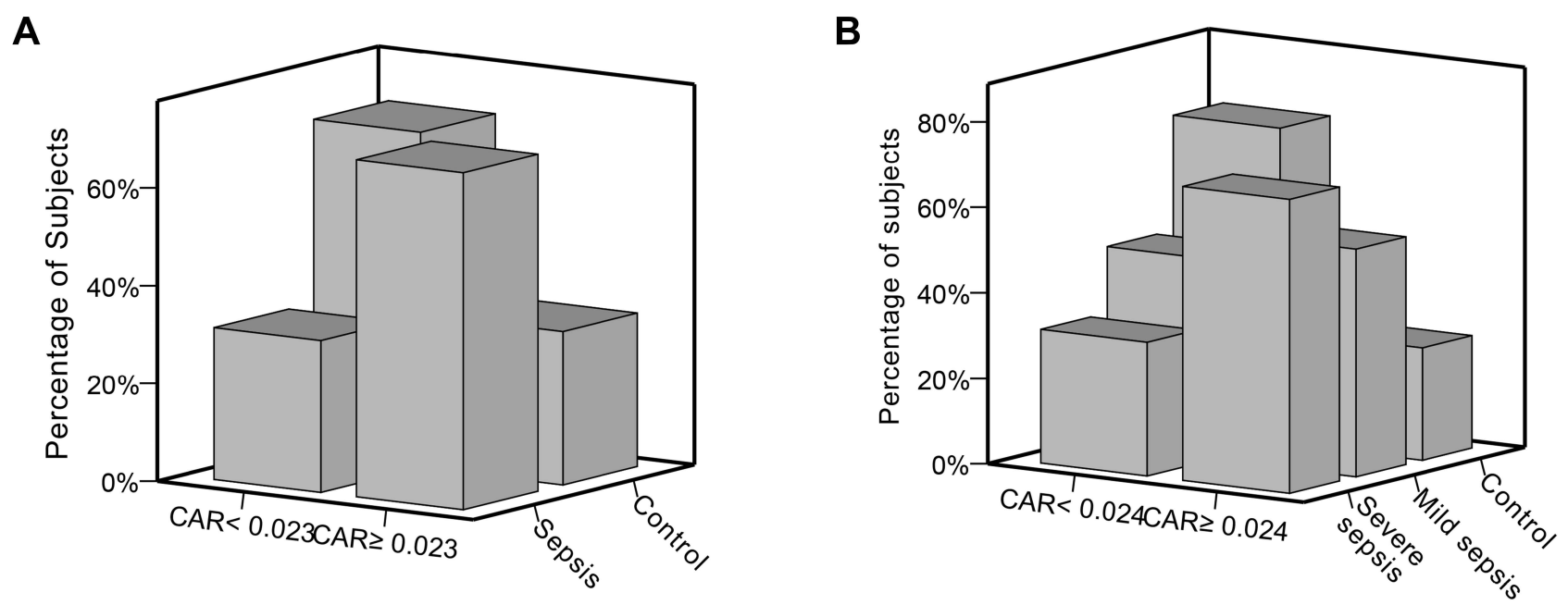

Figure 2 ROC curve of CAR, CRP, and ALB in predicting sepsis and severe sepsis in neonates. (A) The ROC curve for CAR, CRP, and ALB in predicting sepsis. (B) The ROC curve for CAR, CRP, and ALB in predicting severe sepsis.
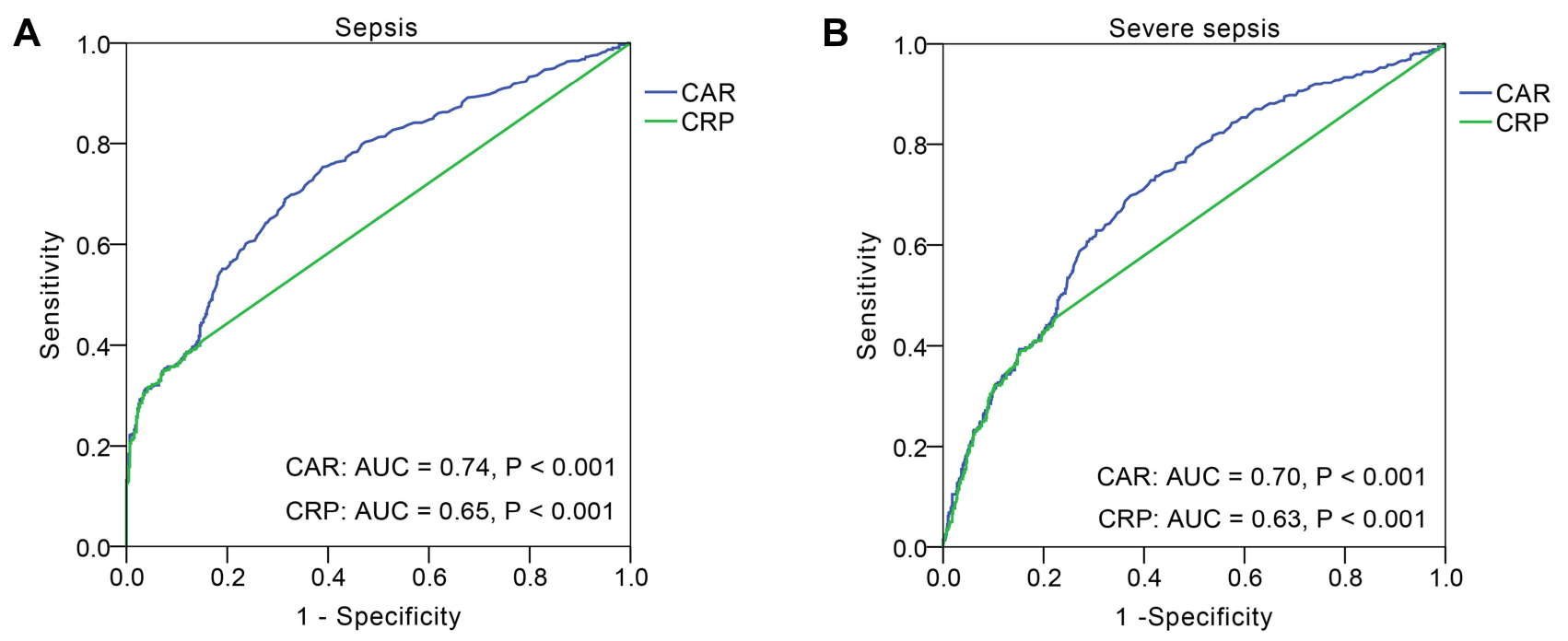

Figure 3 Distribution of neonates in high or low CAR groups. (A) The distribution of neonates with sepsis in high $(\geq 0.023)$ or low (<0.023) CAR groups. (B) The distribution of neonates with severe sepsis in high $(\geq 0.024)$ or low $(<0.024)$ CAR groups.

vomiting, diarrhea and jaundice. ${ }^{4}$ In addition, blood culture, the gold standard for sepsis diagnosis, also has shortcomings in the diagnosis of neonatal sepsis, such as a long waiting time, inadequate volume of blood, and prehospital antimicrobial therapy. ${ }^{6}$ Therefore, we need rapid and sensitive predictors to diagnose neonatal sepsis. We processed the circulating blood biomarkers that may be useful in the early diagnosis of neonatal sepsis. ${ }^{19}$

Sepsis is a systemic inflammatory response syndrome, and biomarkers of infection and inflammation play an important role in predicting the presence of neonatal sepsis. CRP is a traditional inflammatory marker and closely associated with systemic inflammatory status. ${ }^{20}$ Many studies have demonstrated that CRP was a determining risk factor for infection and inflammation-related diseases, such as influenza, pneumonia, sepsis and trauma. ${ }^{9,21,22}$ For neonatal sepsis, CRP was one of the most studied and used laboratory tests, while it suffered from low specificity due to the physiologic rise after birth or non-infectious related conditions. ${ }^{23,24}$ In this study, our data showed that the AUC of CRP in diagnosis of neonatal sepsis was 0.65 , with 35\% sensitivity (data not shown).

ALB is another protein produced by the liver. It can maintain the colloid-osmotic pressure, keep fluid from leaking out of blood vessels, nourishes tissues, and transports hormones, vitamins, drugs, and calcium throughout 
the body. ${ }^{10}$ Traditionally, ALB is regarded as an indicator of malnutrition. However, some studies have shown that ALB was not be a nutrition marker and ALB was not recommended as a nutrition marker by bodies that assess nutrition. $^{25-27}$ Besides, many studies demonstrated that there exists a close correlation between ALB and inflammation. $^{11,12,28}$ Low ALB levels could widely be seen in patients with inflammatory diseases and were associated with more severe inflammation. ${ }^{29,30}$ Sepsis is often complicated with organ dysfunctions. ${ }^{31}$ Sepsis could damage the liver through hemodynamic alterations, assault on the hepatocytes, or both, which further reduced the liver's ability to synthesize with ALB. ${ }^{32}$ Yang et $\mathrm{al}^{33}$ reported that hypoalbuminemia was frequent among neonates with sepsis, and that lower albumin levels might be associated with a poorer prognosis. Lower serum albumin levels were also associated with more severe inflammation. Godinez-Vidal et $\mathrm{al}^{34}$ further reported that ALB was a predictor of severity in adult patients with abdominal sepsis.

In recent years, a wide number of studies have found that the CAR, as an emerging risk factor, was closely related to multiple diseases, such as cancer, cardiovascular diseases, and sepsis. ${ }^{15,35-38}$ Two studies reported that a higher CAR was associated with poor overall survival rates in lung cancer and colorectal cancer adult patients. $^{39,40}$ In addition, it could also be a reliable proinflammation marker for increased coronary thrombus burden, ${ }^{35}$ acute kidney injury development, ${ }^{41}$ coronary artery lesions formation and intravenous immunoglobulin resistance in adults. ${ }^{42}$ In the case of sepsis, Kim et $\mathrm{al}^{43}$ reported that the CAR was an independent predictor of mortality in adult patients with severe sepsis or septic shock. In addition, the CAR can also predict sepsis and prognoses in adult patients with severe burn injuries. ${ }^{15}$

In the present study, we firstly explored the relationship between the CAR and neonatal sepsis in a relatively large population and found that the CAR levels were higher in neonates with sepsis and showed a gradual increase within control, mild sepsis, and severe sepsis groups. According to the CAR tertiles, we divided the neonates into three groups. Data showed that the prevalence of overall, mild and severe sepsis significantly increased from the CAR tertile 1 to tertile 3 ( $\mathrm{P}<0.001)$, especially for the prevalence of overall sepsis (which raised up to $80.2 \%$ ). The multivariate analysis showed that the CAR was an independent predictor for neonatal sepsis and severe sepsis. The ROC curve analysis showed that the CAR had a well discriminatory power in predicting sepsis and severe sepsis.

However, the present study encounters several limitations. First, it is a retrospective single-center study and we did not track the future clinical outcomes in the present study. Prospective studies involving multiple center are necessary to evaluate the CAR as a predictor for neonatal sepsis. Second, we only measured the CAR at admission and believed that serial CAR measurements may be more useful in monitoring neonatal sepsis.

\section{Conclusion}

Our study demonstrated that CAR was an independent predictor for the presence and severity of neonatal sepsis. Higher CAR was positively associated with an increased prevalence of sepsis.

\section{Ethics Approval and Consent to Participate}

The study was conducted according to the guidelines of the Declaration of Helsinki and was approved the Hospital Ethics Review Board of Henan Children's Hospital. We confirmed that all the data were anonymized and maintained with confidentiality; therefore, the requirement for informed consent has been waived because of the retrospective nature of the current study.

\section{Funding}

This work was supported by the Key Research, Development, and Promotion Projects of Henan Province (202102310132), and Medical Science and Technology Project of Henan Province (LHGJ20190970, LHGJ202 00607 and LHGJ20200651).

\section{Disclosure}

Tiewei Li and Xiaojuan Li should be considered co-first authors. The authors report no conflicts of interest in this work.

\section{References}

1. Berg D, Gerlach H. Recent advances in understanding and managing sepsis. F1000Res. 2018;7:1570.

2. Fleischmann C, Scherag A, Adhikari NK, et al. Assessment of global incidence and mortality of hospital-treated sepsis. current estimates and limitations. Am J Respir Crit Care Med. 2016;193(3):259-272. doi:10.1164/rccm.201504-07810C

3. Stevenson EK, Rubenstein AR, Radin GT, Wiener RS, Walkey AJ. Two decades of mortality trends among patients with severe sepsis: a comparative meta-analysis*. Crit Care Med. 2014;42(3):625-631. doi:10.1097/CCM.0000000000000026 
4. Shane AL, Sánchez PJ, Stoll BJ. Neonatal sepsis. Lancet. 2017;390 (10104):1770-1780. doi:10.1016/S0140-6736(17)31002-4

5. Liu L, Oza S, Hogan D, et al. Global, regional, and national causes of child mortality in 2000-13, with projections to inform post-2015 priorities: an updated systematic analysis. Lancet. 2015;385 (9966):430-440. doi:10.1016/S0140-6736(14)61698-6

6. Iroh Tam PY, Bendel CM. Diagnostics for neonatal sepsis: current approaches and future directions. Pediatr Res. 2017;82(4):574-583. doi:10.1038/pr.2017.134

7. Stocker M, van Herk W, El Helou S, et al. C-reactive protein, procalcitonin, and white blood count to rule out neonatal early-onset sepsis within 36 hours: a secondary analysis of the Neonatal Procalcitonin Intervention Study. Clin Infect Dis. 2020. doi:10.1093/cid/ciaa876

8. Povoa P, Almeida E, Moreira P, et al. C-reactive protein as an indicator of sepsis. Intensive Care Med. 1998;24(10):1052-1056. doi: $10.1007 / \mathrm{s} 001340050715$

9. Wang HE, Shapiro NI, Safford MM, et al. High-sensitivity C-reactive protein and risk of sepsis. PLoS One. 2013;8(7):e69232. doi:10.1371/ journal.pone. 0069232

10. Fanali G, Di Masi A, Trezza V, Marino M, Fasano M, Ascenzi P. Human serum albumin: from bench to bedside. Mol Aspects Med. 2012;33(3):209-290.

11. Don BR, Kaysen G. Serum albumin: relationship to inflammation and nutrition. Semin Dial. 2004;17(6):432-437. doi:10.1111/j.08940959.2004.17603.x

12. Arroyo V, García-Martinez R, Salvatella X. Human serum albumin, systemic inflammation, and cirrhosis. $J$ Hepatol. 2014;61 (2):396-407. doi:10.1016/j.jhep.2014.04.012

13. Artigas A, Wernerman J, Arroyo V, Vincent J-L, Levy M. Role of albumin in diseases associated with severe systemic inflammation: pathophysiologic and clinical evidence in sepsis and in decompensated cirrhosis. J Crit Care. 2016;33:62-70. doi:10.1016/j. jcrc.2015.12.019

14. Fleck A, Raines G, Hawker F, et al. Increased vascular permeability: a major cause of hypoalbuminaemia in disease and injury. Lancet. 1985;1(8432):781-784. doi:10.1016/S0140-6736(85)91447-3

15. Yu Y, Wu W, Dong Y, Li J, Steel HC. C-reactive protein-to-albumin ratio predicts sepsis and prognosis in patients with severe burn injury. Mediators Inflamm. 2021;2021:6621101. doi:10.1155/2021/6621101

16. Goldstein B, Giroir B, Randolph A. International pediatric sepsis consensus conference: definitions for sepsis and organ dysfunction in pediatrics. Pediatr Crit Care Med. 2005;6(1):2-8. doi:10.1097/01. PCC.0000149131.72248.E6

17. Li T, Dong G, Zhang M, et al. Association of neutrophil-lymphocyte ratio and the presence of neonatal sepsis. J Immunol Res. 2020;2020:7650713. doi:10.1155/2020/7650713

18. World sepsis day 2017 - preventable maternal and neonatal sepsis a critical priority for WHO and global sepsis alliance. 2017; Available from: https://static1.squarespace.com/static/ $58 \mathrm{a} 7025 \mathrm{~b} 8419 \mathrm{c} 215 \mathrm{~b} 30 \mathrm{~b} 2 \mathrm{df3} / \mathrm{t} / 59 \mathrm{~b} 1 \mathrm{~b} 9 \mathrm{~d} 52994 \mathrm{caee} 6 \mathrm{bc0eba7/}$ 1504819673100/Press_Release_WSD_WSC_English_Letterhead +(PDF).pdf. Accessed September 12, 2017.

19. Sharma D, Farahbakhsh N, Shastri S, Sharma P. Biomarkers for diagnosis of neonatal sepsis: a literature review. J Matern Fetal Neonatal Med. 2018;31(12):1646-1659. doi:10.1080/ 14767058.2017.1322060

20. Sproston NR, Ashworth JJ. Role of C-reactive protein at sites of inflammation and infection. Front Immunol. 2018;9:754. doi:10.3389/fimmu.2018.00754

21. Vasileva D, Badawi A. C-reactive protein as a biomarker of severe H1N1 influenza. Inflamm Res. 2019;68(1):39-46. doi:10.1007/ s00011-018-1188-x

22. Luo X, Zhou W, Yan X, et al. Prognostic value of C-reactive protein in patients with coronavirus 2019. Clin Infect Dis. 2020;71 (16):2174-2179. doi:10.1093/cid/ciaa641
23. Eschborn S, Weitkamp JH. Procalcitonin versus C-reactive protein: review of kinetics and performance for diagnosis of neonatal sepsis. J Perinatol. 2019;39(7):893-903. doi:10.1038/s41372-019-0363-4

24. Hofer N, Zacharias E, Muller W, Resch B. An update on the use of C-reactive protein in early-onset neonatal sepsis: current insights and new tasks. Neonatology. 2012;102(1):25-36. doi:10.1159/000336629

25. Klein S. The myth of serum albumin as a measure of nutritional status. Gastroenterology. 1990;99(6):1845-1846. doi:10.1016/00165085(90)90500-Z

26. Fuhrman MP. The albumin-nutrition connection: separating myth from fact. Nutrition. 2002;18(2):199-200. doi:10.1016/S08999007(01)00729-8

27. Lee JL, Oh ES, Lee RW, Finucane TE. Serum albumin and prealbumin in calorically restricted, nondiseased individuals: a systematic review. Am J Med. 2015;128(9):1023.e1021-1022. doi:10.1016/j. amjmed.2015.03.032

28. Eckart A, Struja T, Kutz A, et al. Relationship of nutritional status, inflammation, and serum albumin levels during acute illness: a Prospective Study. Am J Med. 2020;133(6):713-722.e717. doi:10.1016/j.amjmed.2019.10.031

29. Soeters PB, Wolfe RR, Shenkin A. Hypoalbuminemia: pathogenesis and clinical significance. J Parenter Enter Nutr. 2019;43(2):181-193. doi:10.1002/jpen. 1451

30. Kaysen GA. Biochemistry and biomarkers of inflamed patients: why look, what to assess. Clin J Am Soc Nephrol. 2009;4(Suppl 1):S56S63. doi:10.2215/CJN.03090509

31. Fujishima S. Organ dysfunction as a new standard for defining sepsis. Inflamm Regen. 2016;36:24. doi:10.1186/s41232-016-0029-y

32. Nesseler N, Launey Y, Aninat C, Morel F, Malledant Y, Seguin P. Clinical review: the liver in sepsis. Crit Care. 2012;16(5):235. doi:10.1186/cc11381

33. Yang C, Liu Z, Tian M, et al. Relationship between serum albumin levels and infections in newborn late preterm infants. Med Sci Monit. 2016;22:92-98. doi:10.12659/MSM.895435

34. Godinez-Vidal AR, Correa-Montoya A, Enriquez-Santos D, PerezEscobedo SU, Lopez-Romero SC, Gracida-Mancilla NI. Is albumin a predictor of severity and mortality in patients with abdominal sepsis? Cir Cir. 2019;87(5):485-489.

35. Duman H, Cinier G, Bakirci EM, et al. Relationship between $\mathrm{C}$-reactive protein to albumin ratio and thrombus burden in patients with acute coronary syndrome. Clin Appl Thromb Hemost. 2019;25:1076029618824418. doi:10.1177/1076029618824418

36. Tanriverdi Z, Gungoren F, Tascanov MB, Besli F, Altiparmak IH. Comparing the diagnostic value of the $\mathrm{C}$-reactive protein to albumin ratio with other inflammatory markers in patients with stable angina pectoris. Angiology. 2020;71(4):360-365. doi:10.1177/0003319719897490

37. Karabag Y, Cagdas M, Rencuzogullari I, et al. Relationship between $\mathrm{C}$-reactive protein/albumin ratio and coronary artery disease severity in patients with stable angina pectoris. J Clin Lab Anal. 2018;32(7): e22457. doi:10.1002/jcla.22457

38. Kaplan M, Duzenli T, Tanoglu A, Cakir Guney B, Onal Tastan Y, Bicer HS. Presepsin:albumin ratio and C-reactive protein: albumin ratio as novel sepsis-based prognostic scores: a retrospective study. Wien Klin Wochenschr. 2020;132(7-8):182-187. doi:10.1007/s00508-020-01618-9

39. Deng TB, Zhang J, Zhou YZ, Li WM. The prognostic value of $\mathrm{C}$-reactive protein to albumin ratio in patients with lung cancer. Medicine. 2018;97(50):e13505. doi:10.1097/MD.0000000000013505

40. Liao CK, Yu YL, Lin YC, et al. Prognostic value of the C-reactive protein to albumin ratio in colorectal cancer: an updated systematic review and meta-analysis. World J Surg Oncol. 2021;19(1):139. doi:10.1186/s12957-021-02253-y

41. Karabag Y, Cagdas M, Rencuzogullari I, et al. The C-reactive protein to albumin ratio predicts acute kidney injury in patients with ST-segment elevation myocardial infarction undergoing primary percutaneous coronary intervention. Heart Lung Circ. 2019;28(11):1638-1645. doi:10.1016/j. hlc.2018.08.009 
42. Tsai CM, Yu HR, Tang KS, Huang YH, Kuo HC. C-reactive protein to albumin ratio for predicting coronary artery lesions and intravenous immunoglobulin resistance in Kawasaki disease. Front Pediatr. 2020;8:607631. doi:10.3389/fped.2020.607631
43. Kim MH, Ahn JY, Song JE, et al. The C-reactive protein/albumin ratio as an independent predictor of mortality in patients with severe sepsis or septic shock treated with early goal-directed therapy. PLoS One. 2015;10(7):e0132109. doi:10.1371/journal.pone.0132109

\section{Publish your work in this journal}

The Journal of Inflammation Research is an international, peerreviewed open-access journal that welcomes laboratory and clinical findings on the molecular basis, cell biology and pharmacology of inflammation including original research, reviews, symposium reports, hypothesis formation and commentaries on: acute/chronic inflammation; mediators of inflammation; cellular processes; molecular mechanisms; pharmacology and novel anti-inflammatory drugs; clinical conditions involving inflammation. The manuscript management system is completely online and includes a very quick and fair peerreview system. Visit http://www.dovepress.com/testimonials.php to read real quotes from published authors.

Submit your manuscript here: https://www.dovepress.com/journal-of-inflammation-research-journal 